\title{
The atypical cannabinoid 0-1602 shows antitumorigenic effects in colon cancer cells and reduces tumor growth in a colitis-associated colon cancer model
}

\author{
Julia Kargl ${ }^{1 *}$, Johannes Haybäck², Angela A Stančić ${ }^{1}$, Gunther Marsche ${ }^{1}$ Ákos Heinemann ${ }^{1}$, Rudolf Schicho ${ }^{1}$ \\ From 18th Scientific Symposium of the Austrian Pharmacological Society (APHAR). Joint meeting with the \\ Croatian, Serbian and Slovenian Pharmacological Societies. \\ Graz, Austria. 20-21 September 2012
}

\section{Background}

Cannabinoids and the endocannabinoid system play an important role the protection against inflammation and cancer. O-1602, a synthetic cannabinoid with antiinflammatory properties, has little affinity to classical cannabinoid receptors but shows cannabinoid-like effects. In the present study, we were interested whether O-1602 produces antitumorigenic effects in colon cancer cells and whether it could reduce tumorigenesis in the colon in vivo.

\section{Methods}

We used the cell lines HT-29 and SW480 to study the effect of O-1602 on viability and apoptosis in cancer cells. A mouse model of colitis-associated colon cancer was employed to study the effect of O-1602 on tumor growth in vivo.

\section{Results}

Viability of HT-29 and SW480 cells was decreased and apoptosis was promoted by $\mathrm{O}-1602$ in a concentrationdependent manner $(0.1-10 \mu \mathrm{M})$. In the mouse model, treatment with O-1602 (3 mg/kg, i.p., $12 x$, every second day during a period of 3 weeks) reduced tumor area by $50 \%$ and tumor incidence by $30 \%$. Histological scoring showed a significant decrease in tumor load. In tumor tissue, O-1602 decreased levels of phosphorylated activator of transcription factor 3 (pSTAT3) by $50 \%$ and tumor necrosis factor alpha (TNF- $\alpha$ ) by around $45 \%$. Treatment with O-1602 led to a ten-fold increase in the expression of the tumor suppressor p53.

\section{Conclusions}

O-1602 exerts antitumorigenic effects by targeting colon cancer cells as well as proinflammatory pathways known to promote colitis-associated tumorigenesis, thus providing a novel insight into antitumorigenic mechanisms of atypical cannabinoids. As O-1602 is free of central sedation, it could be an interesting compound for the treatment of colon and possibly other cancers.

\section{Acknowledgements}

Supported the Austrian Science Fund (P22771 to R.S., P22521 to A.H. and P21004 to G.M.), the Austrian National Bank (OeNB 14429 to R.S. and 14263 to A.H.), the Franz Lanyar Foundation (351 to R.S.) and the Innovative Medicines Initiative Joint Undertaking (IMI) Grant (OncoTrack to J.H.). J.K. and A.S. are funded by the PhD program of the Medical University of Graz.

\section{Author details}

'Institute of Experimental and Clinical Pharmacology, Medical University of Graz, 8010 Graz, Austria. Institute of Pathology, Medical University of Graz, 8036 Graz, Austria.

Published: 17 September 2012

doi:10.1186/2050-6511-13-S1-A23

Cite this article as: Kargl et al:: The atypical cannabinoid O-1602 shows antitumorigenic effects in colon cancer cells and reduces tumor growth in a colitis-associated colon cancer model. BMC Pharmacology and Toxicology 2012 13(Suppl 1):A23.

\footnotetext{
* Correspondence: julia.kargl@medunigraz.at

'Institute of Experimental and Clinical Pharmacology, Medical University of Graz, 8010 Graz, Austria

Full list of author information is available at the end of the article
}

(c) 2012 Kargl et al; licensee BioMed Central Ltd. This is an Open Access article distributed under the terms of the Creative Commons 